Supporting Information for:

Electrical Properties of Junctions Between $\mathrm{Hg}$ and Si(111) Surfaces Functionalized with Short Chain Alkyls

Stephen Maldonado, Katherine E. Plass, David Knapp, and Nathan S. Lewis*

Beckman Institute and Kavli Nanoscience Institute

210 Noyes Laboratory, 127-72

Division of Chemistry and Chemical Engineering

California Institute of Technology

Pasadena, California 91125 


\section{Low Temperature $J-V$ measurements}

The Si substrate was placed on a stainless steel platform (thickness $\sim 1 \mathrm{~mm}$ ) and then inserted into the cut-away slot of the base. (Figure S1a) The Si, stainless steel platform, and aluminum base were all in electrical contact. The teflon piece was pressed down by three set screws and a Viton o-ring made a compressed seal with the Si sample. (Figure S1b) A type $\mathrm{K}$ thermocouple (not shown) was fixed to the underside of the stainless steel platform, exposed by the hole in the base plate. $\mathrm{Hg}$ was poured into the center cavity of the teflon top and the entire cell was immersed in a $\mathrm{N}_{2}(l)$ bath. Electrical contact to the $\mathrm{Hg}$ was made with a suspended $\mathrm{Pt}$ wire. Temperatures were recorded manually through a Watlow 96 PID.

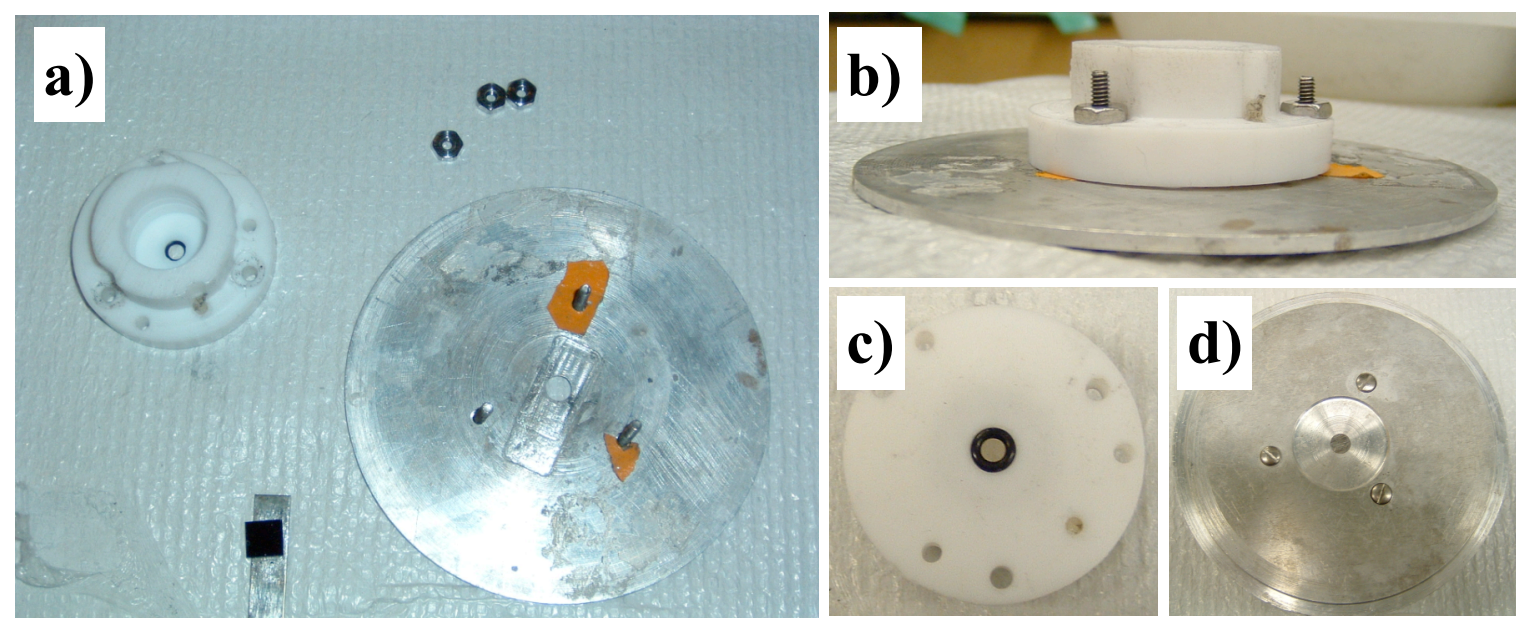

Figure S1. Test cell used to acquire low temperature $J-V$ data. (a) Disassembled cell. (b) Assembled cell. (c) Underside of the teflon top. O-ring area $=0.128 \mathrm{~cm}^{2}$. (d) Underside of the metal base.

\section{Impedance Measurements}

Experimental data were recorded as the total impedance magnitude $(Z)$ and phase angle $(\phi)$ as a function of the frequency of the sinusoidal input waveform. Real ( $\left.Z_{\text {REAL }}\right)$ and imaginary ( $\left.Z_{\text {IMAGINARY }}\right)$ components of the measured impedance were then determined through Equations S1.

$$
\begin{aligned}
& Z_{\text {REAL }}=Z \sin (\phi) \\
& Z_{\text {IMAGINARY }}=Z \cos (\phi)
\end{aligned}
$$

For an equivalent circuit consisting of a resistor $(R)$ and capacitor $(C)$ in parallel, the expected $Z_{\text {REAL }}-Z_{\text {IMAGINARY }}$ relation is hemispherical. ${ }^{1}$ For all tested samples, Nyquist plots (- $Z_{\text {IMAGINARY }}$ vs. $Z_{\text {REAL }}$ ) were generated to assess the applicability of the parallel $R C$ equivalent circuit model. An example plot for a iso $-\mathrm{C}_{3} \mathrm{H}_{7}-\mathrm{Si}(111) / \mathrm{Hg}$ device is presented in Figure S2. All reported values for $\mathrm{Hg} / \mathrm{Si}$ junctions were taken from samples that 
displayed similar Nyquist plot profiles. However, for high barrier height devices, the entire hemispherical profile was not always visible in the investigated frequency range.

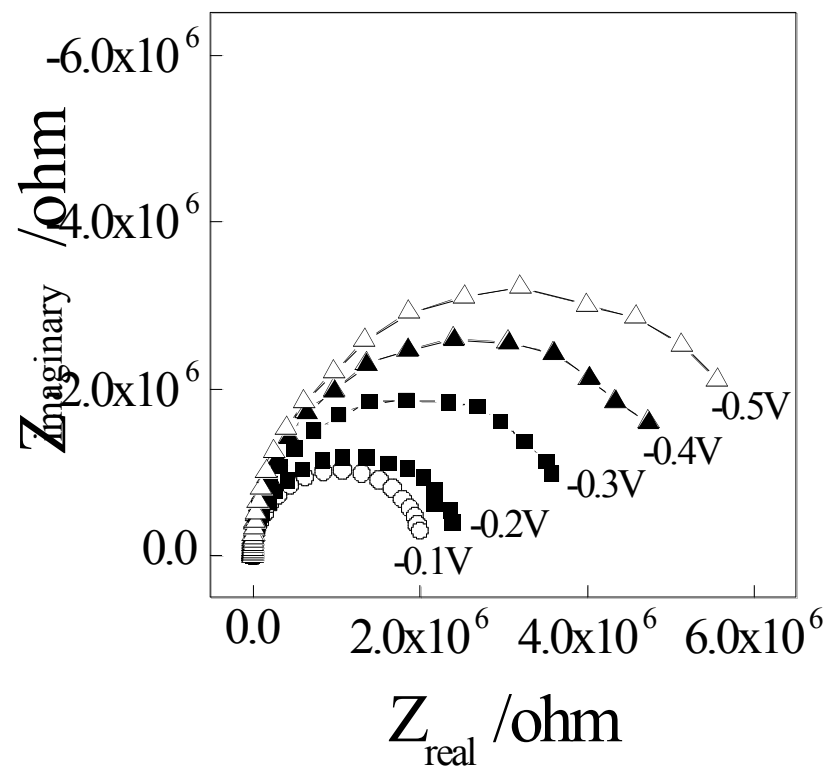

Figure S2. Nyquist plot of imaginary vs. real components of the measured impedance for a $i$ so- $\mathrm{C}_{3} \mathrm{H}_{7}-\mathrm{Si}(111) / \mathrm{Hg}$ device. $f=10^{1}-10^{6} \mathrm{~Hz}$

\section{High Resolution X-Ray Photoelectron Spectra of Chemically Modified Si(111) Surfaces After Contacting with Hg}

High resolution $\mathrm{Si}_{2 p}$ spectra were obtained for $\mathrm{n}-\mathrm{Si}(111)$ surfaces modified with either hydrogen $(-\mathrm{H})$, methyl $\left(-\mathrm{CH}_{3}\right)$, or propynyl $\left(-\mathrm{C} \equiv \mathrm{CH}_{3}\right)$ terminal groups after they had been in contact with $\mathrm{Hg}$ for $\geq 20$ minutes. (Figure S3) The general acquisition conditions were as described in the Experimental Section. The resolution of the spectrometer was insufficient to distinguish completely the $\mathrm{Si}_{2 \mathrm{p}}$ doublet at 100 and $99 \mathrm{eV}$. However, no shoulders at higher binding energies (101-104 eV) indicative of monolayer oxide coverages were observed for any of the three surface preparations, either before or after contacting with $\mathrm{Hg}^{2,3}$ 


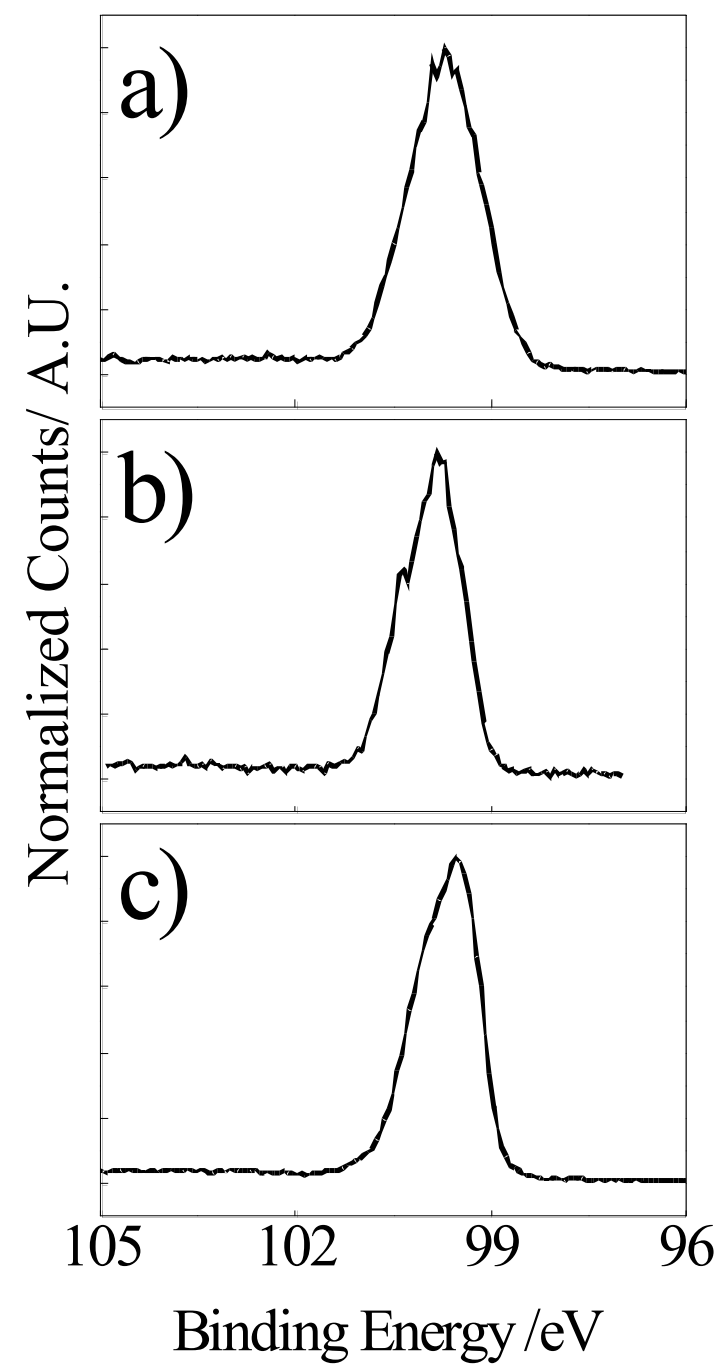

Figure S3. X-ray photoelectron spectra of the Si 2p region of n-Si(111) surfaces with different terminal functionalities following removal of $\mathrm{Hg}$ contact. (a) $-\mathrm{H}$, (b) $-\mathrm{CH}_{3}$, and (c) $-\mathrm{C} \equiv \mathrm{CH}_{3}$.

\section{References}

1. Bard, A. J.; Faulkner, L. R., Electrochemical Methods. John Wiley \& Sons: New York, 2001.

2. $\quad$ Nemanick, E. J.; Hurley, P. T.; Webb, L. J.; Knapp, D. W.; Michalak, D. J.; Brunschwig, B. S.; Lewis, N. S., J. Phys. Chem. B 2006, 110, (30), 14770-14778.

3. Webb, L. J.; Nemanick, E. J.; Biteen, J. S.; Knapp, D. W.; Michalak, D. J.; Traub, M. C.; Chan, A. S. Y.; Brunschwig, B. S.; Lewis, N. S., J. Phys. Chem. B 2005, 109, (9), 3930-3937. 